CASE REPORT

\title{
Novel compound heterozygous mutations in the SBP2 gene: characteristic clinical manifestations and the implications of GH and triiodothyronine in longitudinal bone growth and maturation
}

\author{
Takashi Hamajima, Yuichi Mushimoto ${ }^{1}$, Hironori Kobayashi ${ }^{1}$, Yoshiro Saito ${ }^{2}$ and Kazumichi Onigata ${ }^{1}$ \\ Department of Pediatric Endocrinology and Metabolism, Aichi Children's Health and Medical Center, 1-2 Osakada, Morioka-cho, Obu, Aichi 4748710, \\ Japan, ${ }^{1}$ Department of Pediatrics, Shimane University Faculty of Medicine, Shimane 6938501, Japan and ${ }^{2}$ Department of Medical Life Systems, Faculty of \\ Medical and Life Sciences, Doshisha University, Kyoto 6100394, Japan \\ (Correspondence should be addressed to T Hamajima; Email: takabeachisland@nifty.com)
}

\begin{abstract}
Objective: Mutations in the selenocysteine insertion sequence binding protein 2 gene (SECISBP 2 also known as SBP2) lead to a multisystemic disorder. Our objectives are to examine the clinical manifestations of the present patient and evaluate the effects of $\mathrm{GH}$ and triiodothyronine $\left(\mathrm{T}_{3}\right)$ for longitudinal bone growth and maturation.

Methods: A Japanese boy presented with unusual thyroid function tests (normal or slightly elevated $\mathrm{TSH}$, low-normal or slightly decreased free $\mathrm{T}_{3}\left(\mathrm{FT}_{3}\right)$, and elevated free thyroxine $\left(\mathrm{FT}_{4}\right)$ ), short stature without GH deficiency, and delayed bone maturation. The entire coding region of the patient's SBP2 was analyzed. GH treatment was initiated when the patient was 4 years old, and combination therapy with $\mathrm{GH}$ plus $\mathrm{T}_{3}$ was started when the patient was 10 years old. We monitored the patient's height and bone age until he was 11 years old.

Results: The patient showed typical symptoms of SBP2 deficiency, and novel compound heterozygous mutations were identified in SBP2 (p.M515fsX563/p.Q79X). Six years of GH monotherapy improved the patient's height s.D. from -3.4 to -1.7 without accelerating bone maturation, whereas 6 months of $\mathrm{T}_{3}$ treatment combined with $\mathrm{GH}$ almost normalized the thyroid function tests and improved both longitudinal bone growth and maturation.

Conclusions: In the growth plate, GH may compensate for decreased local $\mathrm{T}_{3}$ effects on longitudinal bone growth; however, GH does not appear to compensate for the effects of $\mathrm{T}_{3}$ on bone maturation. We believe that the present case has important implications for understanding the mechanism of thyroid hormone and $\mathrm{GH}$ on longitudinal bone growth and maturation.
\end{abstract}

European Journal of Endocrinology 166 757-764

\section{Introduction}

Selenium (Se) is an essential nutritional trace element for humans and diverse species (1). The principal physiological roles of Se are exhibited by selenoproteins, which contain selenocysteine (Sec), the main form of Se, within their active sites $(2,3,4,5)$. Twenty-five selenoprotein genes have been identified in humans $(2$, $3,4,5)$. Although not all the functions of selenoproteins have been elucidated, selenoproteins such as glutathione peroxidases (GPx), thioredoxin reductases, and iodothyronine deiodinases have physiological functions in antioxidant defense, oxidoreduction, and thyroid hormone metabolism respectively $(2,3,4,5)$.

Selenoproteins require several specific cis-acting sequences in their mRNA and trans-acting factors for their synthesis $(2,3,4,5,6)$. Although the UGA codon normally operates in translation termination, the UGA codons in the coding region of selenoprotein mRNAs are recoded to Sec $(2,3,4,5)$. A stem-loop structure, Sec insertion sequence (SECIS), in the $3^{\prime}$-UTR is considered to be crucial for this process $(2,3,4,5)$. Furthermore, several trans-acting factors, such as selenocysteyltRNA ${ }^{[\mathrm{ser}] \mathrm{sec}}$, dedicated elongation factor (EFSec), and SECIS binding protein 2 (SECISBP2 also known as SBP2), are indispensable for Sec incorporation into selenoproteins $(2,3,4,5)$.

The iodothyronine deiodinases activate or inactivate thyroid hormone action and are therefore indispensable for the appropriate biological functions of thyroid hormone (7). Three types of iodothyronine deiodinases have been documented in humans. Type 1 and type 2 iodothyronine deiodinases (D1 and D2 respectively) primarily act as activating enzymes of thyroid hormone; conversely, type 3 iodothyronine deiodinase (D3) acts as an inactivating enzyme. Several types of 
deiodinase-deficient transgenic mice, such as D1 knockout, D2 knockout, D3 knockout, and D1/D2 combined knockout mice, have been created; however, no iodothyronine deiodinase mutations have been described in humans (7). Iodothyronine deiodinase metabolic disorders in humans were first described in 2005 by Dumitrescu et al. (6). The patients, who harbored mutations in SBP2, had characteristic abnormalities in thyroid hormone levels (high thyroxine $\left(\mathrm{T}_{4}\right)$, low triiodothyronine $\left(\mathrm{T}_{3}\right)$, and normal or slightly elevated TSH) and had characteristic phenotypes, such as short stature in their childhood and bone maturation delay (6). Similar unusual thyroid hormone patterns and phenotypes have been described in other reports $(8,9,10)$. The more recent reports have documented other symptoms, such as myopathy $(8,10)$, azoospermia (10), and photosensitivity (10), which are caused by the involvement of SBP2 in the production of other selenoproteins.

Here, we describe the case of a Japanese boy with novel compound heterozygous mutations in SBP2. We have followed this patient's clinical course and thyroid function tests since he was 2 years of age. To the best of our knowledge, this report is the first to describe the results of GH treatment in a patient with SBP2 mutations. In addition, we examined the effects of GH monotherapy and combination therapy with $\mathrm{T}_{3}$ plus $\mathrm{GH}$ on longitudinal bone growth and maturation in this patient.

\section{Materials and methods}

\section{Hormonal assays}

Chemiluminescence enzyme immunoassays (Lumipulse TSH-III, $\mathrm{FT}_{3}-\mathrm{N}$, and $\mathrm{FT}_{4}$; Fujirebio, Inc., Tokyo, Japan) were used to measure $\mathrm{TSH}, \mathrm{FT}_{3}$, and $\mathrm{FT}_{4}$. $\mathrm{GH}$ was measured by IRMA (GH kit Daiichi; TFB, Inc., Tokyo, Japan). IGF1 and IGFBP3 were measured by IRMA (Somatomedin C·II Siemens; Siemens Healthcare Diagnostics, Inc., Tokyo, Japan) and RIA (IGFBP3 Cosmic; Cosmic Corporation, Tokyo, Japan) respectively.

\section{Se and selenoprotein assays}

Plasma Se was measured using an atomic absorption spectrophotometer (SPECTR AA220Z; Agilent Technologies, Inc., Tokyo, Japan). Plasma selenoprotein $\mathrm{P}$ (SeP) concentrations were determined using a sandwich ELISA with rat antihuman SeP MABs BD1 and AH5, as described earlier (11). The optical density of the plates was measured at $450 \mathrm{~nm}$ using an OPTImax tunable microplate reader (Molecular Devices, Sunnyvale, CA, USA). All measurements were made in duplicate, and the average value was used. To measure extracellular GPx activities, a coupled enzyme assay, which was performed following the oxidation of NADPH, was used as described earlier (12). The assay conditions were as follows: $0.1 \mathrm{M}$ phosphate buffer, $\mathrm{pH} 7.0,0.2 \mathrm{mM}$
NADPH, $0.5 \mathrm{mM}$ EDTA, $1 \mathrm{mM} \mathrm{NaN}_{3}, 2 \mathrm{mM}$ GSH, 1 unit/ml GSH reductase, and $30 \mu \mathrm{M}$ hydrogen peroxide. The oxidation of NADPH was followed at $340 \mathrm{~nm}$ at $37^{\circ} \mathrm{C}$, and the activity was expressed as nmol of NADPH oxidized per minute.

\section{DNA sequencing and analysis}

Genomic DNA was isolated from peripheral blood lymphocytes by using a DNA Quick II kit (Dainippon Pharmaceuticals, Osaka, Japan). Each exon of SBP2 including the intron/exon boundaries was PCR amplified for 30 cycles using the previously reported conditions (9). The PCR products were purified by using a QIAquick PCR Purification kit (Qiagen GmbH) and sequenced using an ABI PRISM 310 Genetic Analyzer (PE Applied Biosystems, Foster City, CA, USA) or the CEQ 8000 Genetic Analysis System (Beckman Coulter, Inc., Fullerton, CA, USA). The structure of human SBP2 was obtained from the GenBank database (ENSG00000105607).

\section{GH treatment}

The patient was treated with recombinant human GH at the standard Japanese dose for $\mathrm{GH}$ deficiency (0.175 mg/kg per week; Nordiflex; Novo Nordisk A/S, Copenhagen, Denmark). The GH dose was titrated monthly according to the patient's body weight. The levels of IGF1, IGFBP3, and thyroid hormone were examined every 3 months. Bone age was evaluated at least annually by the Greulich-Pyle method or the Tanner-Whitehouse 2 method for Japanese children by the same physician ( $\mathrm{T} \mathrm{H})$.

\section{$T_{3}$ treatment}

Liothyronine sodium (thyronamine; Takeda Pharmaceutical Company Limited, Osaka, Japan; $5 \mu \mathrm{g}$ /day) was given in two divided doses, and we monitored the patient's thyroid function tests, longitudinal bone growth, and bone maturation.

These studies were approved by the ethics committee of Aichi Children's Health and Medical Center, Doshisha University, and Shimane University Faculty of Medicine. Written informed consent for molecular studies, GH treatment, and $\mathrm{T}_{3}$ treatment was obtained from the patient's parents.

\section{Case report}

The patient was born to nonconsanguineous Japanese parents at 39 weeks' gestation after an uncomplicated delivery. At birth, the patient weighed $2784 \mathrm{~g}(-1.1$ S.D.) and was $49.0 \mathrm{~cm}$ in height (0.0 S.D.). Neonatal screening for congenital hypothyroidism on the fifth day of life showed a normal TSH value $(0.4 \mu \mathrm{U} / \mathrm{ml})$. The 
patient's father had Graves' disease and received an antithyroid drug (methimazole); however, no other family members had thyroid diseases. The father's height was $160 \mathrm{~cm}(-1.9$ s.D.), and the mother's height was $145 \mathrm{~cm}$ (-2.5 S.D.) (Fig. 1). The target height of the patient was calculated to be $159 \mathrm{~cm}(-2.0$ S.D.). The patient's mother was a twin sister, and the patient's maternal grandmother also had short stature $(143 \mathrm{~cm})$. The patient had an elder brother and a younger brother, and the elder brother was diagnosed as having pervasive development disorder.

An infant health check at 3 months of age revealed short stature and failure to thrive. The patient's motor and intellectual developments were delayed. He started walking at 1 year 10 months and speaking at 3 years of age. He was referred to Aichi Children's Health and Medical Center due to short stature at 2 years 8 months of age. No goiter or other somatic abnormalities except esotropia was found. His height was $78.5 \mathrm{~cm}(-3.7$ s.D.) and his body weight was $9.4 \mathrm{~kg}(-2.6$ s.D.). At the chronological age of 2 years 8 months, the patient's bone age was 6 months, as determined by the GreulichPyle method. Serum levels of IGF1 and IGFBP3 were normal at $48 \mathrm{ng} / \mathrm{ml}$ (age-related normal range, $11-172 \mathrm{ng} / \mathrm{ml}$ ) and $1.69 \mu \mathrm{g} / \mathrm{ml}$ (age-related normal range, $1.02-2.50 \mu \mathrm{g} / \mathrm{ml}$ ) respectively. The peak $\mathrm{GH}$ response to L-DOPA, clonidine, and arginine was 8.97,

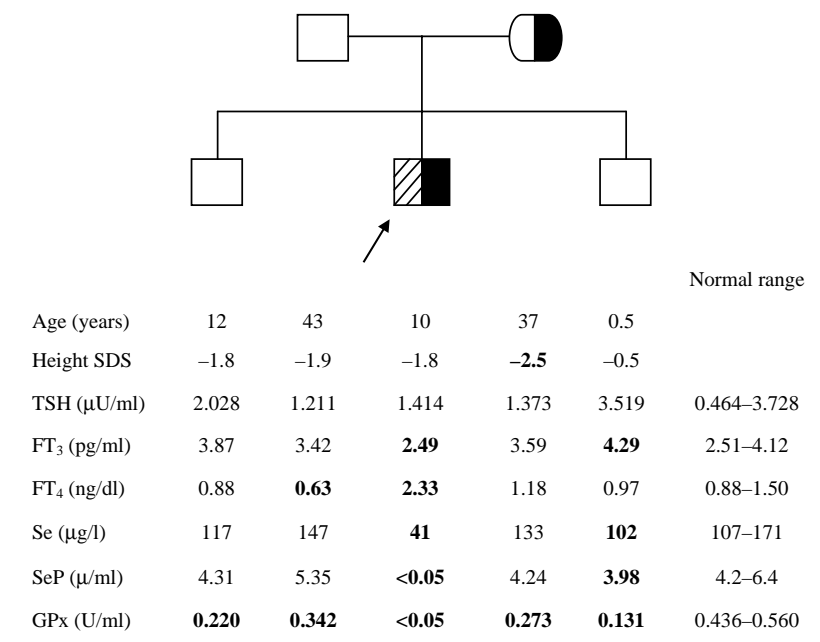

Figure 1 Pedigree, age, height, and laboratory results of the patient and his family. The patient is indicated by an arrow. The entire coding region of SBP2 was examined for all family members. A halfclosed symbol on the right side indicates the Q79X mutation, and a half symbol with diagonal lines on the left side indicates the M515fsX563 mutation. The patient's mother had a heterozygous mutation (Q79X), and the patient harbored compound heterozygous mutations (M515fsX563/Q79X) in SBP2. The father, the elder brother, and the younger brother had no mutations in SBP2. The age, height SDS, and laboratory results are aligned under each symbol in the pedigree. Values outside the normal range are in bold numbers. Only the patient had thyroid hormone values that were characteristic of SBP2 deficiency disorder, such as normal TSH level, low or low-normal $\mathrm{FT}_{3}$ level, and elevated $\mathrm{FT}_{4}$ level.
7.43, and $13.13 \mathrm{ng} / \mathrm{ml}$ respectively. The results of brain magnetic resonance imaging (MRI) were normal.

The serum TSH level was $4.98 \mu \mathrm{U} / \mathrm{ml}$ (normal range, $0.46-3.73 \mu \mathrm{U} / \mathrm{ml})$. The $\mathrm{FT}_{4}$ level was $2.90 \mathrm{ng} / \mathrm{dl}$ (normal range, $0.88-1.50 \mathrm{ng} / \mathrm{dl}$ ), and the $\mathrm{FT}_{3}$ level was $2.28 \mathrm{pg} / \mathrm{ml}$ (normal range, $2.51-4.12 \mathrm{pg} / \mathrm{ml}$ ). The $\mathrm{FT}_{4}$ measurement following equilibrium dialysis was $2.47 \mathrm{ng} / \mathrm{dl}$ (normal range, 0.77-1.93 ng/dl). The results of a $\mathrm{T}_{3}$ provocation test (13) were inconsistent with resistance to thyroid hormone (data not shown), and no mutations were found in THRB. Serum thyroglobulin and autoantibodies to thyroid peroxidase and thyroglobulin were normal (data not shown). Ultrasonography revealed that the thyroid gland was hypoplastic at 10 years of age; the sum of the width of the right and left lobes was $1.4 \mathrm{~cm}$, and the sum of the thickness of the right and left lobes was $1.2 \mathrm{~cm}$ (heightrelated reference range, width $2.4 \pm 0.3 \mathrm{~cm}$ and thickness $1.8 \pm 0.4 \mathrm{~cm})(14)$.

The patient had rotatory vertigo and recurrent exudative otitis media. Audiometric tests performed at 5 and 10 years of age showed bilateral mild conductive hearing loss (15-30 dB in the right ear and 25-35 dB in the left ear). The patient had worn glasses since 1 year 9 months of age because of bilateral hyperopia and esotropia. He often felt fatigued, and cross-sectional T1-weighted MRI at the mid-thigh level at 10 years of age revealed connective tissue and fatty infiltration in the adductor muscle (Fig. 2). The Wechsler intelligence scale for children third edition (WISC-III) showed mild mental retardation. The patient's full-scale IQ was 66 and 70, his verbal IQ was 71 and 80 , and his performance IQ was 68 and 65 at 6 and 10 years of age respectively. A child psychiatrist diagnosed the patient as having mild mental retardation and pervasive development disorders. The patient was a student in a special education class for children with mental retardation. He had no symptoms of photosensitivity.

\section{Results}

We started GH treatment $(0.175 \mathrm{mg} / \mathrm{kg}$ per week) at 4 years 4 months of age because the patient's short stature and bone maturational delay persisted after his first visit to the hospital. (At 3 years 9 months of age, the patient's height S.D. was -3.8 s.D. and his bone age, as evaluated by the Greulich-Pyle method, was 1 year.) Six years of GH treatment resulted in improvement of the patient's height SDS from -3.4 to -1.7 at 10 years 9 months of age; however, his bone age, as evaluated by the Tanner-Whitehouse 2 method for Japanese children, was only 7 years 8 months (Fig. 3 and Table 1). Regarding thyroid function tests, the values of TSH are within the reference range since 6 months after initiating the $\mathrm{GH}$ treatment; however, the unique values of $\mathrm{FT}_{3}$ and $\mathrm{FT}_{4}$ (low-normal and slightly lower $\mathrm{FT}_{3}$ and slightly elevated $\mathrm{FT}_{4}$ ) had hardly changed since the 


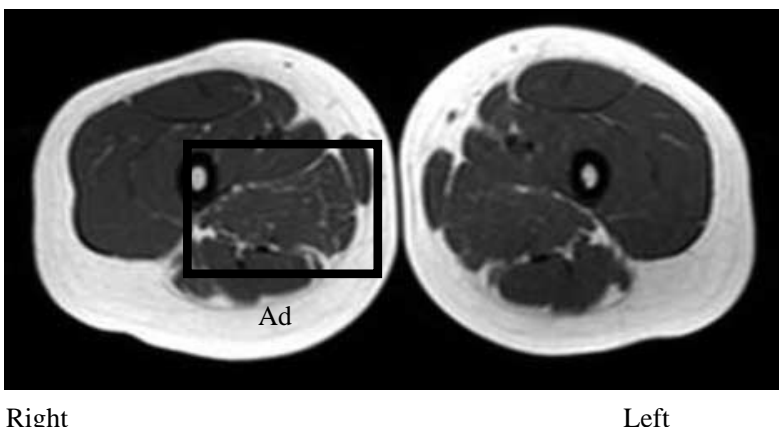

Right

Left

Figure 2 Cross-sectional T1-weighted MRI at the mid-thigh level of the patient at 10 years of age. Connective or fatty tissue infiltration in the adductor muscle (Ad) is shown, particularly in the right leg.

commencement of $\mathrm{GH}$ treatment (Fig. 4A, B and C). The values of IGF1 and IGFBP 3 had remained within the age-related reference range since the beginning of $\mathrm{GH}$ treatment (data not shown).

Although the patient's height SDS was satisfactorily improved by GH treatment, continuous unique abnormalities in the thyroid function tests and the characteristic clinical manifestations prompted us to investigate the SBP2 deficiency disorder. The patient's serum levels of Se, SeP, and GPx were extremely low; however, no other family members showed similar abnormalities (Fig. 1). Sequencing of SBP2 identified novel compound heterozygous mutations in the proband (p.M515fsX563/p.Q79X). A C-to-T transition in codon 79 (c.235C $>\mathrm{T})$, which was inherited from his mother, resulted in the replacement of normal glutamine (CAG) with a stop codon (TAG) in exon 3 (p.Q79X). A $13 \mathrm{bp}$ duplication in exon 11 (c.1529_1541dupCCAGCGCCCCACT) caused the insertion of four amino acids (QRPT); this mutation was a frame-shifting mutation that resulted in a premature stop codon after 48 amino acids (p.M515fsX563). This $13 \mathrm{bp}$ duplication was not identified in any other family members. Both mutations created premature stop codons, and the diagnosis of SBP2 deficiency disorder was confirmed by these results.

We started $\mathrm{T}_{3}$ replacement therapy $(5 \mu \mathrm{g} /$ day, given in two divided doses) at 10 years 11 months of age in addition to GH treatment, and we monitored the patient's thyroid function tests, height SDS, and bone age for 6 months after the initiation of combination therapy. The TSH levels remained in the normal range (Fig. 4A). The $\mathrm{FT}_{3}$ levels increased within the normal range (Fig. 4B), and the $\mathrm{FT}_{4}$ levels decreased to the normal range and then slightly elevated (Fig. 4C). The patient's height SDS improved from -1.8 to -1.6 s.D. during the 6 months of combination therapy. Notably, his bone age advanced 1 year 10 months of age during an 8-month period that included 6 months of combination therapy with GH plus $\mathrm{T}_{3}$ (Fig. 3 and Table 1). The patient's testicular volumes were $3 \mathrm{ml}$ at 11 years 5 months of age.

\section{Discussion}

The proband had characteristic phenotypes of the SBP2 deficiency syndrome. Growth retardation and delayed bone maturation have been documented in the majority of patients with the SBP2 mutations $(6,8,9,10)$. Some degree of developmental delay has been recognized in all the reported patients $(6,8,9,10,15,16)$.

Skeletal muscle involvement, probably due to selenoprotein $\mathrm{N}$ deficiency, has been described in several patients with SBP2 mutations $(8,10)$. Defects in the selenoprotein N gene (SEPN1) cause SEPN1-related myopathy, also called rigid spine muscular dystrophy (17). Some patients with SBP2 mutations had similar muscular findings as patients with defective SEPN1 $(8,10)$. The MRI findings at the mid-thigh level of the present patient were quite similar to the MRI findings from a pediatric case reported by Schoenmakers et al. (10), and interestingly, adductor muscle involvement has been recognized in two other

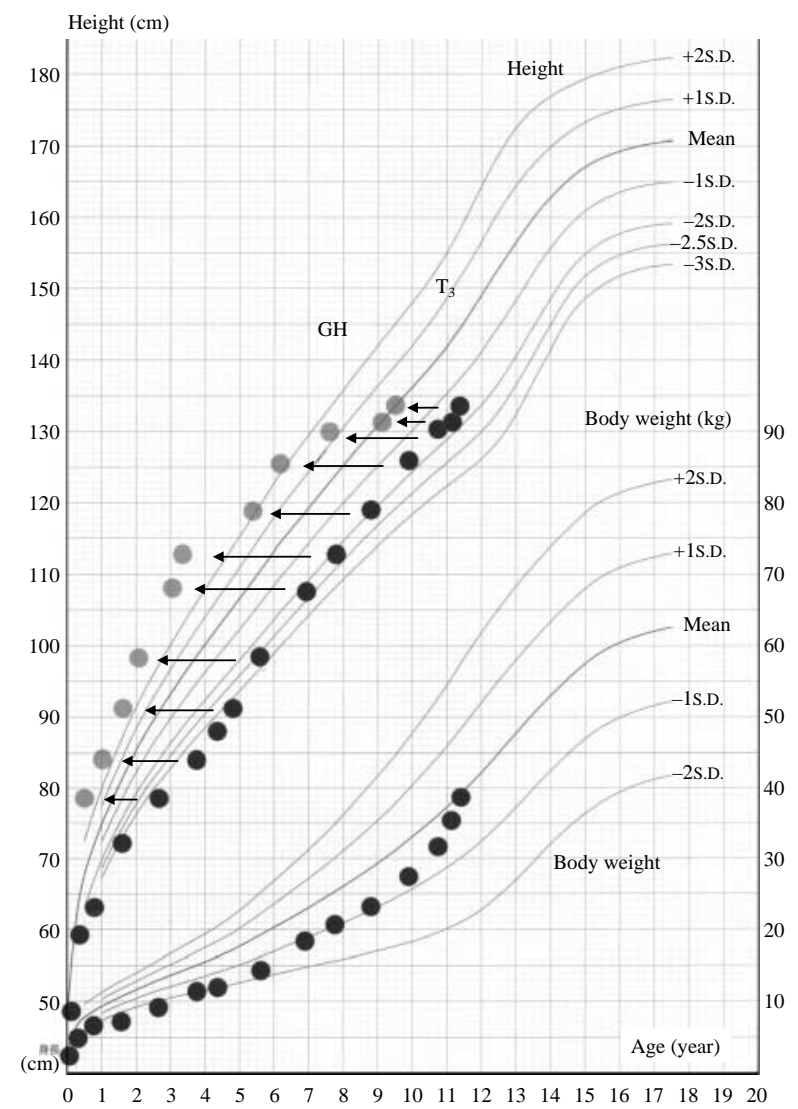

Figure 3 Growth chart and bone age of the patient. Black filled circles show height and body weight. Gray circles show bone age. The two shaded bars show the duration of $\mathrm{GH}$ and $\mathrm{T}_{3}$ treatments. Arrows indicate the gap between chronological age and bone age. Height velocity apparently increased after initiating the $\mathrm{GH}$ treatment; however, a gap of approximately 3 years between chronological age and bone age remained until the commencement of $T_{3}$ treatment. Six months of $T_{3}$ treatment with $\mathrm{GH}$ decreased the gap. We obtained permission to use the growth chart for Japanese boys based on a cross-sectional survey in 2000 (29). 
Table 1 The impact of $\mathrm{GH}$ and $\mathrm{T}_{3}$ treatment on longitudinal bone growth and maturation. Difference indicates the gap between chronological age and bone age.

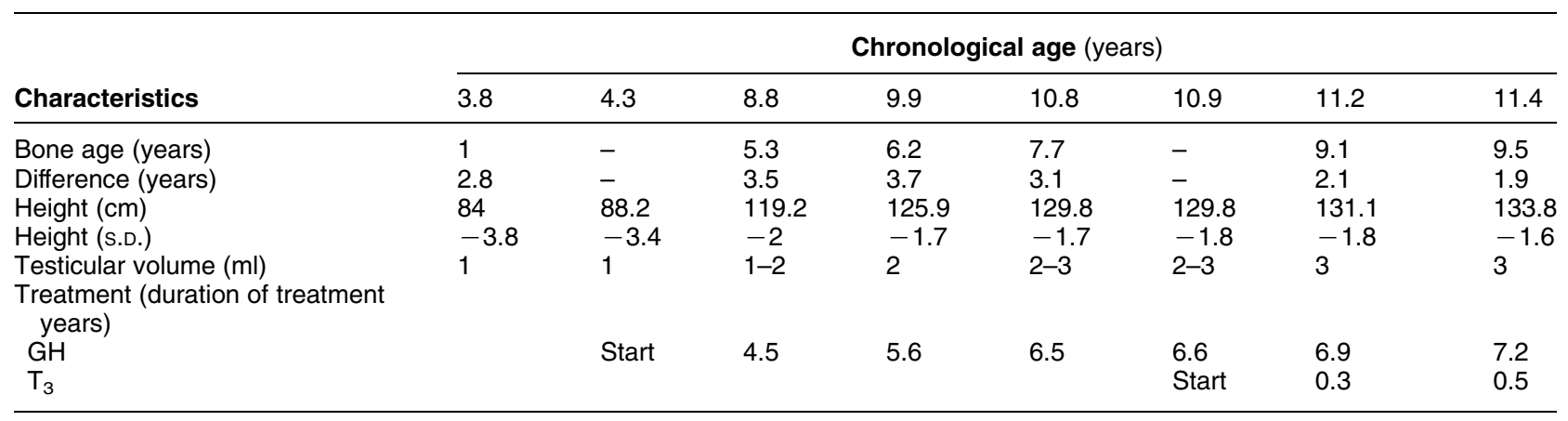

SBP2 deficiency patients with muscle findings $(8,10)$. Thus, adductor muscle involvement may be a characteristic of SBP2 deficiency.

Sensorineural hearing loss has also been documented in a few SBP2-deficient patients $(8,10)$. Observations in mice suggest that there is a relationship between SBP2 deficiency and hearing loss; D2 is expressed in the cochlea before the onset of hearing in mice (18), and hearing loss with retarded cochlear development is found in mice that lack D2 (19). Schoenmakers et al. (10) described two patients (an adult and a child) with SBP2 deficiency disorder with sensorineural hearing loss; hearing impairment of the child was not as severe as that of the adult patient. The authors speculated that the accumulation of reactive oxygen species due to deficiencies in some selenoproteins might have affected the age-related deterioration (10). Although we cannot clarify the relationship between conductive hearing loss and SBP2 deficiency in the present patient, we plan to closely monitor the patient's hearing for age-related hearing deterioration.

All the reported patients with SBP2 mutations have slightly elevated $\mathrm{FT}_{4}$, low or low-normal $\mathrm{T}_{3}$, and normal or slightly elevated TSH levels, probably due to combined reduced enzymatic activities of iodothyronine deiodinases $(6,8,9,10)$. The results of thyroid function tests of any iodothyronine deiodinase knockout mice, such as the D1, D2, D3, and D1/D2 knockout, are not completely equivalent to the reported levels for individuals with SBP2 mutations. The difference may be the result of combined iodothyronine deiodinase defects in SBP2 deficiency, although iodothyronine deiodinase enzymatic activities other than D2 have not been demonstrated in patients with SBP 2 mutation (6). The TSH levels in the present patient were slightly elevated until about 5 years of age and then they became normal (Fig. 4A). The elevated TSH level might have been caused by higher requirements for thyroid hormone during early childhood; alternatively, the normalization of TSH level might have been caused by $\mathrm{GH}$ treatment. GH might have altered the sensitivity of the hypothalamus and/or pituitary to thyroid hormone because the TSH levels decreased to within the normal range a few months after initiating the $\mathrm{GH}$ treatment. $\mathrm{GH}$ usually increases the serum $\mathrm{FT}_{3}$ and decreases $\mathrm{FT}_{4}$ in both levothyroxine-treated and normal individuals; these changes are probably due to increased $\mathrm{T}_{4}$ to $\mathrm{T}_{3}$ conversion (20). However, the present patient's thyroid hormone levels hardly changed since the commencement of $\mathrm{GH}$ therapy. This result may suggest a deficiency in the activities of iodothyronine deiodinases.
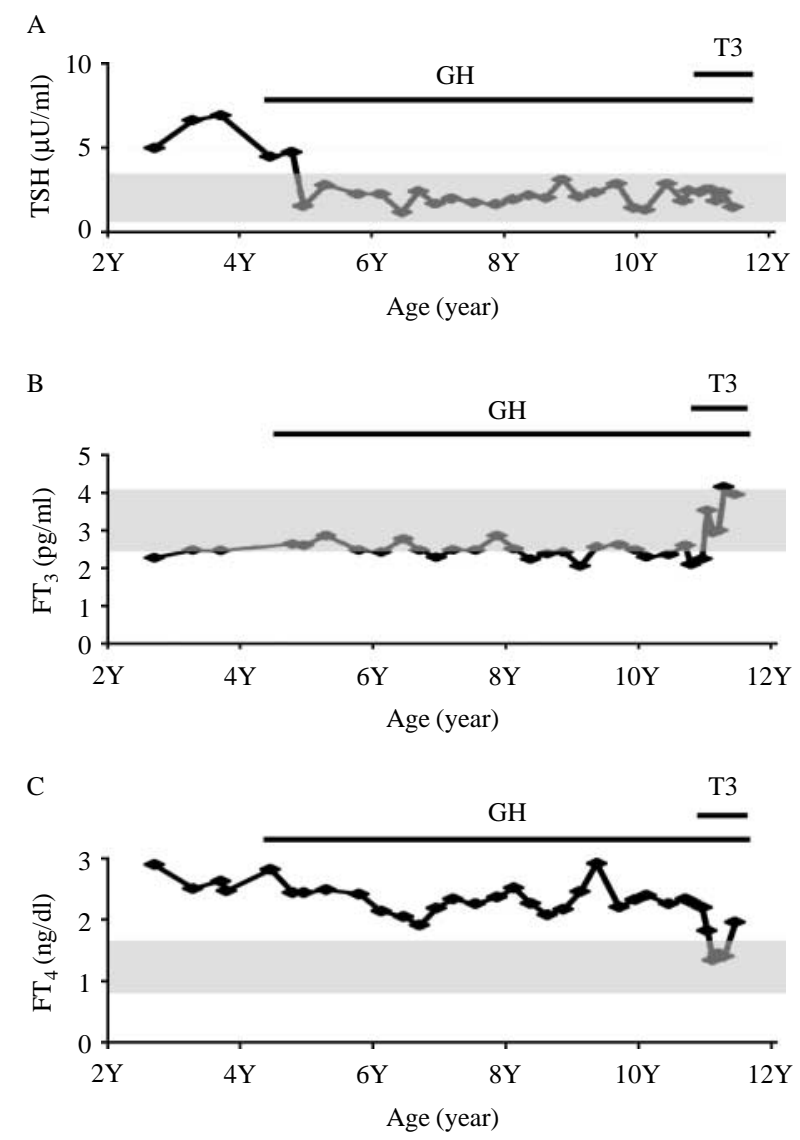

Figure 4 The levels of $\mathrm{TSH}(\mathrm{A}), \mathrm{FT}_{3}(\mathrm{~B})$, and $\mathrm{FT}_{4}(\mathrm{C})$ of the patient from 2 to 11 years of age. The reference ranges are shown as shaded areas. The duration of $\mathrm{GH}$ and $\mathrm{T}_{3}$ treatments is shown by horizontal bars. 
These unique values of thyroid hormone and TSH are important clues in the diagnosis of SBP2 deficiency. Additionally, all the reported child probands, except for one case reported by Azevedo et al. (8), visited the hospital due to short stature $(6,9,10)$. We believe that this is a crucial opportunity for clinicians to examine the possibility of SBP2 deficiency in young children because pediatricians usually examine thyroid hormone and bone age during general screening for short stature.

All the reported patients with SBP2 biallelic mutations had low levels of Se, SeP, and GPx (6, 8, 9, $10)$, and the present patient also had extremely low levels (Fig. 1). The patient's younger brother had slightly low levels in these indices (Fig. 1); however, he did not have any mutations in SBP2. We assume that these slightly low Se and selenoprotein levels may be due to his young age, although there are no reference values for selenoprotein levels during infancy.

Human SBP2 has 854 amino acids and 17 exons (21). In rat $S b p 2$, amino acids $399-517$ are specifically required for Sec insertion, and amino acids 517-777 are required for RNA binding to SECIS; therefore, amino acids 399-777 are considered to be the minimal functional domain (22). The overall percentage of amino acid sequence identity of the human sequence vs the rat sequences is 73 . There are two blocks of high homology between the human and the rat sequences; human SBP2 residues 479-543 and 620-777 have 92 and $95 \%$ amino acid sequence identity with rat $S b p 2$ respectively (21).

A handful of subjects with SBP2 mutations have been reported; however, neither hot spots nor common mutational types have been recognized $(6,8,9,10)$. Dominant negative effects of truncated proteins are unlikely because all the reported heterozygous individuals are normal.

The present patient had novel compound heterozygous mutations in SBP2 (p.M515fsX563/p.Q79X). The allele with the M515fsX563 mutation is predicted to undergo nonsense-mediated mRNA decay and lose its function because it creates a novel stop codon in exon 12. However, the allele with the Q79X mutation is likely to maintain several of the functions of SBP2 despite its premature termination. Di Cosmo et al. (9) demonstrated that the R128X mutation in exon 3 produced smaller SBP2 functional molecules with the essential domains by alternative translation from different downstream AUGs. The allele with the Q79X mutation may have the ability to produce the functional smaller SBP2 proteins similar to the allele with the R128X mutation, and these active isoforms may contribute to the relatively mild phenotype of the present patient.

Although almost all the reported patients with SBP2 mutations exhibited short stature in childhood, no GH-deficient patients have been documented, and the growth retardation is considered to be transient and depends on the residual activity of SBP2 (9). Decreased SBP2 activity may lead to some degree of growth impairment due to unknown roles of selenoproteins. The heights of the three affected individuals in the first reported family ranged from less than the 1 st percentile to the 3rd percentile during growth and from the 1 st to the 10th percentile in adulthood. The heights of the four unaffected siblings ranged from the 3rd to the 25th percentile during growth and from the 10th to the 50th percentile in adulthood (15). The present patient's mother was heterozygous for the SBP2 mutation and showed short stature. It is difficult to clarify the relationship between her short stature and the mutation because she had multiple factors that may have affected her short stature, such as family history of short stature and her birth history of having a twin sibling.

Slightly decreased $\mathrm{T}_{3}$ levels probably affect the growth and ossification retardation in SBP2-deficient subjects. Thyroid hormone is essential for normal skeletal development and maturation (23). Thyroid hormone has both direct and indirect effects on the growth plate. In cell culture, thyroid hormone acts directly on the growth plate chondrocytes to promote hypertrophic differentiation (24). Furthermore, thyroid hormone promotes chondrocyte differentiation in mouse ATDC5 cells and stimulates endochondral ossification in fetal mouse tibias through the local conversion of $\mathrm{T}_{4}$ to $\mathrm{T}_{3}$ by D2 in the growth plate (25). In addition to these direct effects, thyroid hormone indirectly acts on the growth plate via increasing GH and IGF1 secretion (26).

Several treatments (e.g. Se supplementation and $\mathrm{L}_{-} \mathrm{T}_{3}$ replacement) have been attempted to improve height s.D. and normalize thyroid hormone levels in SBP2 deficiency. Se supplementation failed to increase the height SDS and failed to normalize thyroid hormone levels (9). On the other hand, $\mathrm{L}-\mathrm{T}_{3}$ replacement therapy may provide some beneficial effects. Di Cosmo et al. (9) reported that $\mathrm{T}_{3}$ replacement increased both height S.D. and bone age and narrowed the gap between chronological age and bone age. Schoenmakers et al. (10) reported that normal $\mathrm{FT}_{3}$ levels following the commencement of $\mathrm{T}_{3}$ treatment were associated with improved linear growth, speech, and neurodevelopment in a male child. In contrast, Dumitrescu et al. (15) reported that $\mathrm{T}_{3}$ replacement for 8 months had no obvious effect on growth; however, this negative result might have been caused by the patient's age (13.5 years).

GH treatment $(0.175 \mathrm{mg} / \mathrm{kg}$ per week $)$ increased the height SDS by +1.6 s.D. in 5 years without accelerating bone maturation in the present patient. These positive effects on longitudinal growth, mediated by GH, correspond to the findings by Kindblom et al. (27), who found that GH replacement increased longitudinal bone growth but did not normalize growth plate endochondral ossification in thyroid hormone receptor $\alpha 1-, \beta 1-$, and $\beta 2$-deficient mice. Furthermore, Huang et al. (28) reported that increased local IGF1 production by $T_{3}$ is essential for the anabolic effects of thyroid hormone in mice osteoblasts. These reports and the findings in the present case suggest that $\mathrm{GH}$ could 
compensate for decreased $\mathrm{T}_{3}$ anabolic effects on longitudinal bone growth to some extent; however, GH could not compensate for delayed ossification without a sufficient level of $\mathrm{T}_{3}$. Indeed, 6-month $\mathrm{T}_{3}$ replacement therapy apparently advanced the bone maturation and slightly increased the height SDS in the present patient (Table 1 ). We believe that $\mathrm{T}_{3}$ replacement therapy in patients with SBP2 mutations accelerates both the longitudinal bone growth and maturation. However, there are no data on the final height of SBP2-deficient patients who receive $\mathrm{T}_{3}$ replacement therapy. Close growth monitoring is indispensable when SBP2 deficiency is treated with $\mathrm{T}_{3}$, because the rapid advancement of bone age may result in rapid epiphyseal fusion and compromise the adult height.

In conclusion, the patient in the present case had novel compound heterozygous mutations in SBP2 and exhibited symptoms and laboratory results that were characteristic of SBP2 deficiency. Although further investigations are required, we believe that the present case has important implications for understanding the mechanism of thyroid hormone and GH on longitudinal bone growth and maturation.

\section{Declaration of interest}

The authors declare that there is no conflict of interest that could be perceived as prejudicing the impartiality of the research reported.

\section{Funding}

This research did not receive any specific grant from any funding agency in the public, commercial or not-for-profit sector.

\section{References}

1 Rayman MP. The importance of selenium to human health. Lancet $2000 \quad 356$ 233-241. (doi:10.1016/S0140-6736(00) 02490-9)

2 Hoffmann PR \& Berry MJ. Selenoprotein synthesis: a unique translational mechanism used by a diverse family of proteins. Thyroid 200515 769-775. (doi:10.1089/thy.2005.15.769)

$3 \mathrm{Lu} \mathrm{J} \&$ Holmgren A. Selenoproteins. Journal of Biological Chemistry 2009284 723-727. (doi:10.1074/jbc.R800045200)

4 Papp LV, Lu J, Holmgren A \& Khanna KK. From selenium to selenoproteins: synthesis, identity, and their role in human health. Antioxidants \& Redox Signaling 20079 775-806. (doi:10.1089/ ars.2007.1528)

5 Reeves MA \& Hoffmann PR. The human selenoproteome: recent insights into functions and regulation. Cellular and Molecular Life Sciences 200966 2457-2478. (doi:10.1007/s00018-009-0032-4)

6 Dumitrescu AM, Liao XH, Abdullah MS, Lado-Abeal J, Majed FA, Moeller LC, Boran G, Schomburg L, Weiss RE \& Refetoff S. Mutations in SECISBP2 result in abnormal thyroid hormone metabolism. Nature Genetics 200537 1247-1252. (doi:10.1038/ ng1654)

7 Gereben B, Zavacki AM, Ribich S, Kim BW, Huang SA, Simonides WS, Zeold A \& Bianco AC. Cellular and molecular basis of deiodinase-regulated thyroid hormone signaling. Endocrine Reviews 200829 898-938. (doi:10.1210/er.2008-0019)
8 Azevedo MF, Barra GB, Naves LA, Ribeiro Velasco LF, Godoy Garcia Castro P, de Castro LC, Amato AA, Miniard A, Driscoll D, Schomburg L \& de Assis Rocha Neves F. Selenoprotein-related disease in a young girl caused by nonsense mutations in the SBP2 gene. Journal of Clinical Endocrinology and Metabolism 201095 4066-4071. (doi:10.1210/jc.2009-2611)

9 Di Cosmo C, McLellan N, Liao XH, Khanna KK, Weiss RE, Papp L \& Refetoff S. Clinical and molecular characterization of a novel selenocysteine insertion sequence-binding protein 2 (SBP2) gene mutation (R128X). Journal of Clinical Endocrinology and Metabolism 200994 4003-4009. (doi:10.1210/jc.2009-0686)

10 Schoenmakers E, Agostini M, Mitchell C, Schoenmakers N, Papp L, Rajanayagam O, Padidela R, Ceron-Gutierrez L, Doffinger R, Prevosto C, Luan J, Montano S, Lu J, Castanet M, Clemons N, Groeneveld M, Castets P, Karbaschi M, Aitken S, Dixon A, Williams J, Campi I, Blount M, Burton H, Muntoni F, O’Donovan D, Dean A, Warren A, Brierley C, Baguley D, Guicheney P, Fitzgerald R, Coles A, Gaston H, Todd P, Holmgren A, Khanna KK, Cooke M, Semple R, Halsall D, Wareham N, Schwabe J, Grasso L, Beck-Peccoz P, Ogunko A, Dattani M, Gurnell M \& Chatterjee K. Mutations in the selenocysteine insertion sequence-binding protein 2 gene lead to a multisystem selenoprotein deficiency disorder in humans. Journal of Clinical Investigation $2010 \mathbf{1 2 0}$ 4220-4235. (doi:10.1172/ JCI43653)

11 Saito Y, Watanabe Y, Saito E, Honjoh T \& Takahashi K. Production and application of monoclonal antibodies to human selenoprotein P. Journal of Health Science 200147 346-352. (doi:10.1248/jhs. 47.346)

12 Takebe G, Yarimizu J, Saito Y, Hayashi T, Nakamura H, Yodoi J, Nagasawa S \& Takahashi K. A comparative study on the hydroperoxide and thiol specificity of the glutathione peroxidase family and selenoprotein P. Journal of Biological Chemistry 2002 277 41254-41258. (doi:10.1074/jbc.M202773200)

13 Refetoff S, Weiss RE \& Usala SJ. The syndromes of resistance to thyroid hormone. Endocrine Reviews 199314 348-399. (doi:1210/ edrv-14-3-348)

14 Ueda D, Mitamura R, Suzuki N, Yano K \& Okuno A. Sonographic imaging of the thyroid gland in congenital hypothyroidism. Pediatric Radiology 199222 102-105. (doi:10.1007/BFO 2011305)

15 Dumitrescu AM, Di Cosmo C, Liao XH, Weiss RE \& Refetoff S. The syndrome of inherited partial SBP2 deficiency in humans. Antioxidants E Redox Signaling 201012 905-920. (doi:10.1089/ ars.2009.2892)

16 Duntas LH. On the trail of the SBP2-syndrome: clues in a Daedalean maze. Journal of Clinical Endocrinology and Metabolism 201095 3618-3621. (doi:10.1210/jc.2010-1325)

17 Moghadaszadeh B, Petit N, Jaillard C, Brockington M, Roy SQ, Merlini L, Romero N, Estournet B, Desguerre I, Chaigne D, Muntoni F, Topaloglu H \& Guicheney P. Mutations in SEPN1 cause congenital muscular dystrophy with spinal rigidity and restrictive respiratory syndrome. Nature Genetics 200129 17-18. (doi:10. 1038/ng713)

18 Campos-Barros A, Amma LL, Faris JS, Shailam R, Kelley MW \& Forrest D. Type 2 iodothyronine deiodinase expression in the cochlea before the onset of hearing. PNAS 200097 1287-1292. (doi:10.1073/pnas.97.3.1287)

$19 \mathrm{Ng} \mathrm{L,} \mathrm{Goodyear} \mathrm{RJ,} \mathrm{Woods} \mathrm{CA,} \mathrm{Schneider} \mathrm{MJ,} \mathrm{Diamond} \mathrm{E,}$ Richardson GP, Kelley MW, Germain DL, Galton VA \& Forrest D. Hearing loss and retarded cochlear development in mice lacking type 2 iodothyronine deiodinase. PNAS $20041013474-3479$. (doi:10.1073/pnas.0307402101)

20 Salvatore D, Davis TF, Schlumberger MJ, Hay ID \& Larsen PR. Thyroid physiology and diagnostic evaluation of patients with thyroid disorders. In Williams Textbook of Endocrinology, 12th edn, ch 11, p 348. Eds Melmed S, Polonsky KS, Larsen PR \& Kronenberg HM. Philadelphia, PA: Saunders Elsevier, 2011.

21 Lescure A, Allmang C, Yamada K, Carbon P \& Krol A. cDNA cloning, expression pattern and RNA binding analysis of 
human selenocysteine insertion sequence (SECIS) binding protein 2. Gene 2002291 279-285. (doi:10.1016/S0378-1119 (02)00629-7)

22 Copeland PR, Stepanik VA \& Driscoll DM. Insight into mammalian selenocysteine insertion: domain structure and ribosome binding properties of Sec insertion sequence binding protein 2. Molecular and Cellular Biology 200121 1491-1498. (doi:10.1128/MCB.21. 5.1491-1498.2001)

23 Brent GA, Larsen PR \& Davies TF. Hypothyroidism and Thyroiditis. In Williams Textbook of Endocrinology, 11th edn, pp 381-382. Eds Kronenberg HM, Melmed S, Polonsky KS \& Larsen PR. Philadelphia, PA: Saunders Elsevier, 2008.

24 Robson H, Siebler T, Stevens DA, Shalet SM \& Williams GR. Thyroid hormone acts directly on growth plate chondrocytes to promote hypertrophic differentiation and inhibit clonal expansion and cell proliferation. Endocrinology 2000141 3887-3897. (doi:10.1210/en.141.10.3887)

25 Miura M, Tanaka K, Komatsu Y, Suda M, Yasoda A, Sakuma Y, Ozasa A \& Nakao K. Thyroid hormones promote chondrocyte differentiation in mouse ATDC5 cells and stimulate endochondral ossification in fetal mouse tibias through iodothyronine deiodinases in the growth plate. Journal of Bone and Mineral Research 200217 443-454. (doi:10.1359/jbmr.2002.17.3.443)
26 Ohlsson C, Isgaard J, Tornell J, Nilsson A, Isaksson OG \& Lindahl A. Endocrine regulation of longitudinal bone growth. Acta Paediatrica 199382 (Suppl 391) 33-40 discussion 41. (doi:10.1111/j.16512227.1993.tb12925.x)

27 Kindblom JM, Gothe S, Forrest D, Tornell J, Vennstrom B \& Ohlsson C. GH substitution reverses the growth phenotype but not the defective ossification in thyroid hormone receptor alpha 1-/ - beta - / - mice. Journal of Endocrinology 2001 171 15-22. (doi:10.1677/joe.0.1710015)

28 Huang BK, Golden LA, Tarjan G, Madison LD \& Stern PH. Insulin-like growth factor I production is essential for anabolic effects of thyroid hormone in osteoblasts. Journal of Bone and Mineral Research 200015 188-197. (doi:10.1359/jbmr.2000.15.2.188)

29 Ito Y, Kato N, Tachibana K \& Fujieda K. The year 2000 version of standard growth table and chart based on the standard height adopted by national treatment research project for chronic pediatric disease. Shonika shinryo 20057 1343-1351 (in Japanese).

Received 16 September 2011

Revised version received 4 January 2012

Accepted 13 January 2012 